\title{
EL COMISARIO COMO ARTISTA. DE CUANDO SE CUESTIONAN SUS LÍMITES ${ }^{1}$
}

\author{
ADRIÁN CONTRERAS GUERRERO. \\ Universidad de Granada
}

Resumen

La figura del comisario de exposiciones encierra en sí misma, muchas de las atribuciones que consideramos propias del artista. El presente texto pretende llamar la atención sobre la "artisticidad" que puede estar presente en la obra del comisario, tarea en la cual nos saldrán al paso autores tan destacados como el siempre genial Oscar Wilde, quien en su conocido ensayo "El crítico como artista" -que da nombre a este trabajo-, trató de construir un alegato ciertamente paralelo.

\section{Palabras clave}

Museología, comisariado de exposiciones, gestión cultural, habilidad artística, arte contemporáneo.

\section{THE CURATOR AS ARTIST. QUESTIONING ABOUT ITS LIMITS}

\section{Abstract}

The figure of the curator encloses many of the powers that we regard as proper of the artist. This text aims to draw attention to the artistry that is present in the work of the curator, a task in which we will be accompanied by important authors as the always great Oscar Wilde, who in his famous essay "The Critic as Artist" -which baptise this paper- tried to build a parallel argument.

Keywords

Museology, curatorship, cultural management, artistry, contemporary art.

\footnotetext{
${ }^{1}$ No puedo dejar de manifestar mi agradecimiento a Laura Arias Serrano, cuyas clases en la Universidad Complutense de Madrid, despertaron en mí algunas de las reflexiones aquí contenidas.
} 


\section{Actualidad de la figura del comisario}

El presente trabajo orbita sobre tres realidades que atañen al artefacto artístico: la génesis, el conocimiento y la presentación del mismo. En principio suponemos bien diferenciadas estas tres parcelas: la génesis de la obra corresponde al artista creador, el conocimiento de dicha obra, al historiador, que la investiga y documenta, mientras que la presentación es ejercida por el comisario - $\mathrm{O}$ en su defecto por el conservador de turno-. Pero esta normalizada separación es, como veremos, inocente. Sondearemos las concurrencias actuales entre todas estas labores, siendo el motivo privilegiado de nuestro discurso el tercero de estos personajes.

Hoy la figura del comisario y sus prácticas son una realidad poliédrica. Hay quienes entienden la exposición como un campo de demostración para dar a conocer los resultados de una investigación, quienes buscan en el espacio expositivo un campo para la investigación en sí mismo $^{2}$, pero también quienes la asimilan a una máquina de guerra ${ }^{3}$ o los que incluso reclaman su status de obra de arte. En ello el papel del comisario es esencial y sus posiciones van desde la pretendida neutralidad de los que apuestan por el comisario-cero ${ }^{4}$ o no-comisariado a lo que podríamos llamar "comisariado de autor".

En lo que parecen coincidir los más diversos comisarios es en el carácter experimental y abierto que tiene hoy la exposición, sirviendo para plantear cuestiones, no para dar resultados inamovibles. Citamos por poner un ejemplo, lo que dice Didi-Huberman:

En el caso de una exposición es el espectador el que, enfrentado a las distintas relaciones posibles que propone esa muestra, debe construir sus determinaciones (...) No hay dogma aquí, sino montaje (...) En esto debería consistir una exposición, en un ensayo basado en relaciones entre imágenes que en principio son infinitas, que pueden ser repensadas una y otra vez ${ }^{5}$.

Estos planteamientos acordes a una sociedad que cada vez valora más las experiencias que van acompañadas de adjetivos como "interactivo", "comunitario" o "participativo", no pueden sin embargo difuminar el indispensable protagonismo que ostenta el comisario en la exposición, narración visual y experiencial que responde a su intencionalidad, pues él es el verdadero articulador del discurso ofrecido al espectador.

Sin embargo, ni la figura del comisario ni sus atribuciones están aún codificadas suficientemente, como sí lo está la del crítico de arte, ampliamente reconocida desde Diderot y Baudelaire. La madurez alcanzada ya desde épocas tempranas por la crítica artística manifestada en la siempre sana costumbre del auto-cuestionamiento, tiene su plasmación más reveladora en la revisión que Oscar Wilde hace de la misma en su ensayo titulado El crítico como artista, de 1890. En varios momentos volveremos sobre este autor y sobre esta obra para fundamentar nuestro discurso. Contrapuesta a la disciplina de la crítica artística, el comisariado de exposiciones sin embargo parece que no acaba de encontrar su formulación. Como ya dijera Christophe Cherix ${ }^{6}$, "a pesar de la actual proliferación de cursos en estudios del comisariado, no cabe destacar ninguna metodología auténtica ni ningún legado claro". El papel del comisario, continúa argumentando Cherix "aparece incorporado a profesiones preexistentes relacionadas con el arte, como director de museo (Johannes Caldders, Jean Leering o Franz Meyer), marchante (Seth Siegelaub, por ejemplo) o crítico de arte (Lucy Lippard)".

\footnotetext{
${ }^{2}$ MOLINS DE LA FUENTE, Patricia: "Las exposiciones temporales como campo de investigación en el museo de arte contemporáneo". En Arbor: Ciencia, pensamiento y cultura, No 717, 2006, págs. 83-86.

3 DIDI-HUBERMAN, Georges: "La exposición como máquina de guerra: keywords". En Minerva. Revista del Círculo de Bellas Artes, no. 16, 2011, págs. 24-28.

${ }^{4}$ GROY, Boris: “On the Curator-ship”. En Art Power, Cambridge, MIT Press, 2008, pág. 44.

${ }^{5}$ DIDI-HUBERMAN, Georges: 2011, págs. 28.

${ }^{6}$ Prólogo de Christophe Cherix en ULRICH OBRIST, Hans: Breve historia del comisariado, España, Exit, 2010, págs. 9-13.
} 
Por otra parte, confeccionar una definición del comisario, sería quizá, un ejercicio poco provechoso, ya que es una acepción en proceso de sedimentación, aún no cristalizada. Y es que las concomitancias entre las figuras del comisario y del artista están aún por dilucidar. De hecho, ¿hay fronteras entre el comisario y el artista?

La exposición se valora cada vez más, como una forma de expresión artística, pues "exponer también significa proponer, ofrecer, desplegar el resultado de un trabajo". En la actualidad, el diseño de exposiciones se solapa con movimientos artísticos, tales como el arte ambiental, el arte de las instalaciones y o el de interpretación. Decía Arthur Danto que:

(...) la definición del curador ha cambiado desde la perspectiva de alguien que tiene a su cuidado una colección -cuidador, para usar el término inglés- al curador independiente que tiene que concebir una exposición y encontrar las vías para poder realizarla. Es en este sentido que los curadores se han convertido más y más en artistas que trabajan con las obras.7

\section{El artista y el comisario eran una misma persona}

Como se deduce de los datos de los que disponemos, y por propia lógica, encontramos que antes de la dispersión de las funciones creativa y expositiva, ambas se hallaban reunidas en la persona del artista. Para ilustrar esta afirmación podríamos remontarnos más en el tiempo, pero sin necesidad de ello, resaltemos algunos precedentes anteriores a las vanguardias históricas, momento clave que como en tantas otras cuestiones de la historia artística supondría un claro punto de inflexión en el orden de las cosas. Elegimos para ello el caso paradigmático de nuestro primer pintor, Velázquez, de quien podemos decir que ejerció lo que hoy llamaríamos "labores curatoriales" una vez que el rey Felipe IV le encargó la reordenación de las colecciones reales, tanto del Real Monasterio de El Escorial ${ }^{8}$ como del Alcázar madrileño, "musealizando" estancias tan emblemáticas como la Pieza Ochavada. Quizá sea éste uno de los primeros puntos de encuentro reseñables entre las figuras del artista y del comisario en nuestro país.

Ya en el siglo XIX y mudando el ámbito geográfico, otro artista, esta vez un arquitecto, iría un paso más allá. En las continuas polémicas en torno a la manera de concretar la presentación definitiva del Altes Museum de Berlín, Karl Friedrich Schinkel estableció unas directrices comunes para todos los elementos que intervienen en la formalización del proyecto: acabados arquitectónicos, accesorios, mobiliario, información, etc., en una concepción global que un siglo después desarrollarían los movimientos de integración. Todo fue proyectado como un conjunto, aunque con los criterios historicistas propios de su tiempo.

Esta experiencia evidencia ya como el artista se preocupa no sólo de la creación de las obras de arte sino también de la forma en que se perciben por parte de la persona que las enfrenta. Sin embargo, las fronteras entre comisario y artista vendrían a transfigurarse definitivamente en el periodo de las vanguardias históricas. De hecho como afirma Cherix ${ }^{10}$ el arte de finales de siglo XIX y el del siglo XX está profundamente entrelazado con la historia de las exposiciones. María Bolaños ${ }^{11}$ por su parte observa que "ni siquiera las corrientes más anti-museísticas renunciaron al fértil campo de agitación que representaba una muestra bien

\footnotetext{
${ }^{7}$ GUASCH, Anna María: 2006. P. 114. La crítica dialogada: entrevistas sobre arte y pensamiento actual (2000-2006), Murcia, Cendeac, 2006, pág. 114.

${ }^{8}$ CHECA CREMADES, Fernando: Felipe II, Mecenas de las artes, Madrid, Nerea, 1992, pág. 462.

${ }^{9}$ En el curso histórico del arte podemos señalar momentos similares: antes habían tenido lugar experiencias como la búsqueda de la "obra de arte total", durante el Barroco, y después arquitectos modernistas trabajaron en sus proyectos concretando incluso los más mínimos detalles como puertas, vitrales o mobiliario. Es el caso de Gaudí en la Casa Calvet o la Casa Batlló para las que diseñó los sillones homónimos, excelentes ejemplos de mobiliario modernista de corte naturalista.

${ }^{10}$ CHERIX, C. en ULRICH OBRIST, Hans: 2010, págs. 10-11.

${ }^{11}$ BOLAÑOS, María (ed.): La memoria del mundo. Cien años de museología 1900-2000, Gijón, Trea, 2002, pág. 118.
} 
aprovechada", y en efecto las corrientes surrealista y dadaísta fueron las que más incidieron en el cambio de paradigma expositivo. La Primera Feria Internacional Dadá organizada en 1920 en la Galería Burchard de Berlín por Grosz, Hausmann y Heartfield, evidenció que la forma de exponer podía llegar a ser tan caótica y anti-convencional como las propias obras, convirtiéndose en uno de los rasgos más característicos de su espíritu provocador y su estética subversiva. Así mismo, la Exposición Internacional del Surrealismo de 1938 se convertiría en una verdadera ruptura con el lenguaje expositivo tradicional: en ella cada objeto sólo podía ser entendido como parte de un conjunto. La iluminación era escasa, del techo colgaban multitud de sacos de carbón mientras que algunas piezas estaban colocadas en ángulos insólitos, y se dispuso un mar rodeado de helechos y cañas en el suelo de una de las salas, con cuatro camas en las esquinas.

Ante estas experiencias, que en principio están a mitad de camino entre la creación de la obra de arte y la presentación pública de la misma, nadie negaría que el montaje de conjunto era en sí mismo, una obra de arte. El surrealismo por su propio carácter seguiría ahondando en estas cuestiones y en 1942 se presentaría la muestra First Papers of Surrealism, preparada por Breton en el Whitelaw Reid Mansion, edificio cuyo estilo ecléctico tanto desagradaba a los defensores del nuevo estilo ${ }^{12}$. Marcel Duchamp camufló el aspecto del salón cubriendo el techo con cuerdas entrecruzadas que iban de un lado a otro de las paredes, lo que dificultaba incluso la visión de los cuadros expuestos.

Otro hito asociado al patrocinio innovador de Peggy Guggenheim fue el novedoso lenguaje que Friedrich Kiesler utilizaría para concebir su galería Art of This Century en las que el artista austriaco unió las facetas de diseñador y de museógrafo. Continuó abriendo la brecha en los nuevos planteamientos, tanto en la organización espacial y el tipo de pared curvas-, como en la relación del cuadro con su soporte ya que éste se proyectaba hacia el espectador sobre brazos ajustables. En la misma línea de ruptura con el lenguaje museológico tradicional se situó Andy Warhol ya en la década de los setenta, revolucionando las prácticas de exposición artística con Raid the Icebox. El título de la exposición era un juego de palabras que hacía referencia a muchas de las zonas frías de almacenamiento de los museos, llenas de objetos que el público no ve. Creó un conjunto muy poco convencional de exhibiciones, colocando pinturas en el suelo apoyadas contra la pared, apiladas en grupos, mientras que exhibía zapatos en masa en un enorme gabinete, que podían ser vistos y tocados como si se encontraran en el propio armario de la persona. Esta forma peculiar de exposición aunque subvertía muchos de las reglas tradicionales, sobre todo lo que puso de manifiesto es que su verdadera pieza era la labor de comisariado.

Otra práctica habitual donde podemos rastrear la implicación curatorial de los artistas, se da a partir del s. XIX cuando cristaliza la valoración moderna del artista. La conciencia de que sus obras habrían de acabar en las salas de los museos, lleva a muchos artistas a intervenir activamente en este proceso de adecuación. Es el caso de Sir John Soane quien realizó multitud de intervenciones museográficas en materia de iluminación, exposición y arquitectura, en el edificio que hasta ese momento había sido su casa-taller, y desde 1813 funcionaba como academia y museo para el estudio de la disciplina arquitectónica, aunque continuó viviendo en unas habitaciones privadas del inmueble. Los artistas no sólo mostraron interés por las condiciones de percepción en sala sino que también se cuidaron las cuestiones discursivas. Así desde 1896, Gustave-Moreau comenzó a concebir su casa como esa "gran obra" que sería su museo, eligiendo y clasificando sus cuadros para que todos los temas que había tratado estuviesen presentes. Pero quizá el caso más paradigmático sea el de Brancusi, quien al final de su vida dejó de producir esculturas para centrarse únicamente en las relaciones que se establecían entre las ya realizadas, y de éstas con el espacio de su taller. Inquietud que le hizo reacio a desprenderse de sus esculturas, y si lo hacía las reemplazaba por reproducciones. Nos dejó como testigos de esta preocupación, sus propias

${ }^{12}$ La galerista Peggy Guggenheim calificó dicho edificio de "horrendo y pasado de moda". Citado en ÁVILA, Ana: El arte y sus museos, Barcelona, Ediciones del Serbal, 2003, pág. 341. 
fotografías en las que se expresan estos estudios de relaciones lumínicas y espaciales tan sugerentes.

En 1968 el artista minimalista Donald Judd, instaló en un inmueble del Soho de Nueva York una exposición permanente, tanto de sus obras como de otros escultores a los que admiraba, pues entendía que era deber del artista preocuparse de cómo se visualizaban las obras pues era también parte del proceso creativo. Y en la misma línea, aunque en unas coordenadas muy diferentes, hay que entender el Teatro-Museo Dalí en Figueras, que siendo del gusto del excéntrico artista no podía haber sido sino como es, un personalísimo contenedor museístico a la vez que una elocuente pieza artística per se: "el objeto surrealista más grande del mundo".

La intervención activa de los artistas en la conformación de esos espacios de demostración que son los museos, fue una de las reacciones que provocó durante los años sesenta y setenta del siglo XX la tendencia reaccionaria que se ha venido a llamar "la crítica institucional", por la que se cuestionaban no sólo las instituciones museísticas, sino también el mercado y el sistema del arte en general. La otra postura convirtió al museo en un objeto en miniatura, cuyo precedente es Marcel Duchamp que entre 1935 y 1941 realizó numerosas ediciones de su Caja en una maleta o Bôite-en-valise, y que ya en 1934 había creado The Green Box. Ambas piezas consistían en una maleta portátil que contenía reproducciones en miniatura de sus obras. En esta misma línea trabajaron Joseph Cornell y posteriormente Marcel Broodthaers, el colectivo Fluxus o Andy Warhol. Su enunciación teórica podríamos buscarla en la obra de André Malraux, que expone en su premonitoria idea del Museo Imaginario (1947), algunos de sus rasgos distintivos.

\section{El comisario asume parcelas artísticas}

Como hemos visto hasta ahora, las confluencias de las figuras del artista y del comisario son muchas, y parece claro que cuando el artista es el que lleva a cabo las labores de musealización de las piezas, ya sean propias o ajenas, el resultado se considera "artístico", es decir que podríamos considerarlo como una obra de arte. Pongamos ahora nuestra atención en una casuística diferente: ¿Qué ocurre si el comisario no es un artista? Si asistiéramos a una exposición -y podemos imaginar cualquiera de las que tengamos más a mano-, seguramente diríamos que los objetos que se nos presentan ordenados según un determinado discurso, son artísticos. ¿Pero estaríamos dispuestos a admitir que la exposición en sí misma es una obra de arte?

Tomemos un par de ejemplos que estén algo alejados en el tiempo y nos permitan así, tomar la perspectiva suficiente para pensarlo con mayor objetividad. Como observa Carmen Bernárde ${ }^{13}$, muchas veces se ha vinculado a Beuys con Marcel Duchamp, estableciendo con ello una relación que planea sobre el arte del siglo XX: Duchamp en su primera mitad; Beuys en la segunda. Coincidiendo con una exposición en la galería Claude Givaudan en París en 1967, Marcel Duchamp era interrogado acerca del correcto montaje de sus ready-mades. Duchamp, irreverente por naturaleza, contestó:

Eso no es importante. Los ready-mades carecen de destino absoluto, es decir, de una presentación absolutamente necesaria. (...) Es simplemente, para los ready-made, una forma diferente de montarlos con la perspectiva de la proyección que da la luz. Y además, para dar un poco de alegría a una cosa un poco solemne... ${ }^{14}$

Ante esta indiferencia, en apariencia indecente de Marcel Duchamp, que como observa Isabel Tejeda ${ }^{15}$ parece decir: "Ahí le dejo una firma, y así le parezcan máquinas solteras o molinillos de café, apáñeselas como pueda", encontramos la postura de Beuys a quién

\footnotetext{
13 BERNÁRDEZ SANCHÍS, Carmen: Joseph Beuys, Madrid, Nerea, 2003, pág. 17.

14 TEJEDA MARTÍN, Isabel: El montaje expositivo como traducción. Fidelidades, traiciones y hallazgos en el arte contemporáneo desde los años 70, Madrid, Trama, 2006, pág. 82.

15 TEJEDA MARTÍN, Isabel: 2006, pág. 101.
} 
siempre le preocupó el montaje de sus obras en sala, ocupándose personalmente del mismo siempre que pudo. En la contraposición de estas dos actitudes quedan expresadas las diferentes posturas que toman los artistas frente a la futura manipulación de sus obras por parte del comisario. Así, el artista puede dejar la pieza abierta intencionadamente y cederle parcelas de autoría y de decisión al comisario. Cuando esto ocurre el curador puede aprovechar ese margen de acción para aportar su impronta personal al proyecto de una manera más libre. Es precisamente en éste sentido en el que Oscar Wilde afirma -en boca de Gilbert en su citado ensayo El crítico como artista- que "[la crítica] ve a la obra de arte como punto de partida para una nueva creación" ". Si a efectos de nuestra argumentación, sustituyéramos en la afirmación citada, "la crítica" por "el comisariado", no estaríamos faltando en punto alguno a aquello que Wilde quería expresar.

\section{El comisario deviene en artista}

Si bien podemos afirmar que el artista en su proceso creativo, selecciona unos determinados componentes, y los dispone de una cierta forma -teniendo en cuenta las relaciones entre las partes, los valores cromáticos generados, sus tensiones o su simbolismocon la finalidad de que formen un determinado discurso; no es menos cierto que esto al fin y al cabo es lo que hace el comisario: seleccionar ciertas obras de arte para una muestra, optando por una museografía o forma de presentación concreta, de modo que expresen una proposición.

Podríamos hablar de la similitud entre los procesos creativos del comisario y del artista analizando sus fases, pero ya se han señalado en estudios precedentes las características del proceso creativo en general, del que el comisariado forma parte. Citamos por ejemplo el de Sabina Gau: Elproceso de creación artística: diálogo con lo inefable ${ }^{1 t}$. Nos limitamos ahora a subrayar que también para el caso del comisario existen esas tres fases que Günter Regel distingue en el proceso creador: la pre-productiva, la productiva y la post-productiva. Aunque este esquema tripartito puede ser muy matizado, porque existen varias subfases, y advierte de entrada que éstas no se desarrollan de forma sucesiva y ordenada, sino que se pueden superponer y alternar.

En el caso del curador la fase pre-productiva, anterior al proceso de creación en sí, estaría relacionado por una parte con la formación académica, experiencia profesional y/o conocimientos acumulados por el curador, y por otra, con la experiencia vital y sensorial que acumulada influirá decisivamente en los aspectos más subjetivos del proceso que lleva a cabo el comisario, que pueden ir desde su preferencia por una obra, autor o movimiento artístico sobre otros a la elección de una determinada forma de montaje por "sugerirle" una cierta sensación.

En la fase productiva se plantea ya la problematización y su desarrollo, así como la búsqueda de una solución y de los medios expresivos que mejor atiendan a ese fin. Es decir comprende tanto la fase de documentación, investigación y reflexión sobre el tema de la exposición, así como su concreción final: concreción de la tesis argumental con pretensiones comunicativas y concreción de su presentación en sala.

Parece pues, que el comisario en su quehacer lleva a cabo una relectura -de una corriente artística, un periodo, un autor o una idea-, y esto puede hacerlo de manera más o menos neutra, pudiendo aparecer de forma muy patente su personalidad o posición frente a aquello que se expone. Pero entonces, ¿podemos enunciar la artisticidad del curador? Parece arriesgado. Lo que sí estamos en condiciones de afirmar es que hay ciertos paralelismos entre sus funciones creativas. Nos referimos a conceptos como composición, selección o distribución, que se dan tanto en el hecho artístico como en el expositivo.

\footnotetext{
16 WILDE, Oscar: El crítico como artista, Madrid, Espasa Calpe, 2000, págs. 17-18.

17 GAU PUDELKO, Sabina: El proceso de creación artística: diálogo con lo inefable, La Laguna Universidad de La Laguna, 2003.
} 
Es en éste sentido que Niki de St. Phalle dijo en cierta ocasión de Pontus Hultén que "[tiene] alma de artista, no de director de museo" 18 . En efecto, Hultén siempre sostuvo un diálogo muy especial con los artistas aunque él no lo fuera, mientras que otra importante figura de la escena artística como Arthur Danto afirmaba lo siguiente: "en ocasiones he comisariado alguna muestra, pero raramente he aceptado tales invitaciones porque no dispongo de una verdadera imaginación curatorial”, ${ }^{, 19}$.

\section{A modo de cierre}

Este camino que hemos venido realizando juntos se detiene aquí en lo evidente. A modo de cierre, y con el apoyo de Wilde, intentaré apuntar finalmente las bases de una de las creencias personales que me han rondado últimamente: el comisario es un artista.

Pienso que el curador puede llegar a hacer de su obra, efectivamente, una pieza artística. En él se da la intención comunicativa y la transmisión de una idea que debe llevar a cabo a través de unos ciertos materiales. Tanto en el caso del artista como en el del comisario se da la manipulación de estos materiales, ¿qué más da que estos sean unos pigmentos aglutinados sobre un lienzo, objetos encontrados que se unen en un ready-made u obras de arte que forman una exposición?

Si tomamos como referente el ready-made parecen claras las concomitancias entre éste y un montaje expositivo, pero podemos remontarnos bastante en el tiempo encontrando incluso en la antigüedad clásica unos lineamientos reveladores. Entre las ideas de Platón ya planeaba un concepto ciertamente semejante, que influiría la práctica artística decimonónica. El concepto de mundo platónico está regido por un demiurgo, es decir un dios ordenador -no creador al estilo cristiano-, que posee todos los modelos de acuerdo a los cuales se va a organizar la realidad. Platón nos dice que la realidad que percibimos ordenadamente, está efectivamente ordenada porque existe un modelo al que se debe de ajustar: el mundo de la ideas. El Romanticismo retomará estos postulados, y distinguiendo entre el dios platónico y el cristiano surgirán dos tipos diferentes de artista: el artista-dios que crea de la nada y otro tipo de artista, que sólo ordena los materiales. El comisario según el razonamiento que venimos siguiendo encajaría dentro de esta segunda clase. Y de Platón al neoplatonismo, Plotino incluso justificaría la existencia de un "artista director" que no haga manualmente sus obras, a cuyas directrices trabajen otros, primando la concepción de una idea sobre su materialización:

El escultor va dando forma a la piedra siguiendo la huella de la forma inteligible que intuye. Es superior la intuición misma al hecho de picar poco a poco la piedra. Se podría dar el caso de un gran poeta, o un gran escultor, en cuanto a la belleza de sus concepciones, pero que no tuviesen la habilidad suficiente para plasmarlas en las palabras o en la piedra rebelde ${ }^{20}$.

Lo que intento decir no tiene nada de temerario: el comisariado también es creador. Trabaja con una materia prima y le da una nueva forma. Ya se han planteado análisis semejantes. Amerighi reflexionaba al respecto en los siguientes términos:

Si hoy el artista conceptualiza la creación más que fabricarla, si recrea más que crea, si reutiliza materiales generados por la propia sociedad o por el propio contexto artístico en su beneficio, o si simplemente los reordena bajo un criterio particular, y si llega a

\footnotetext{
${ }^{18}$ Citado en ULRICH OBRIST, Hans: 2010, pág. 39.

${ }^{19}$ GUASCH, Anna María: 2006, pág. 114.

${ }^{20}$ BORREGO PIMENTEL, Enrique María: Cuestiones plotinianas, Granada, Biblioteca Teológica Granadina, 1994, pág. 76.
} 
coordinar exposiciones, suyas o de otros, ¿'es tan grande la distancia que le separa del comisario?21

Este mismo autor comenta las dos reacciones que los artistas han demostrado ante la creciente importancia de la figura del comisario y sus atribuciones. Mientras el artista Antonio Saura se refería a ellos como "déspotas incitadores de las modas" y "hacedores de reputaciones y de desahucios" que usan en muchos casos la obra de los artistas para ilustrar "tesis partidistas tan caprichosas como gratuitas", otros muchos creadores se han sentido siguiendo las palabras de Amerighi- atraídos y subyugados desde el primer momento por las formas con las que el discurso curatorial se apropiaba de sus creaciones o de las de otros ${ }^{22}$.

Oscar Wilde ${ }^{23}$ añadiría a lo dicho que al ser el comisario creador como el artista, cuya obra en efecto puede que no tenga más mérito que el de sugerirle algún nuevo estado de pensamiento y de sentimiento al curador, éste puede proceder a su relectura realizándolo con una distinción de forma igual o quizá mayor, y al que dará una belleza diferente. ¿Por qué entonces no puede lograr un producto más alto, con mayores resonancias? No hay nada licencioso en afirmar esto último. El buen comisario como "el buen crítico" de Wilde, "colma de maravilla una forma que el artista puede haber dejado vacía o incomprendida, o sólo entendida en parte" ${ }^{24}$. A este respecto, cabría preguntarnos si no vale más una buena museografía que una mala obra de arte. De hecho, hay museos basados íntegramente en la museografía como el Museo Judío del Holocausto en Berlín. Ese puede ser uno de los extremos. A veces usos semejantes han sido criticados, arguyendo que "ante la falta de contenidos o de ideas, el diseño museográfico suele tomar el protagonismo absoluto" ${ }^{\text {, }}$, tachando esta práctica de "cretinismo museístico". En cualquier caso, nosotros no hablamos de museografías vacías, sino de la creación discursiva del comisario confeccionada a partir de la creación individual del artista o de los artistas. Ciertamente, el montaje museográfico es protagonista, pero sólo en tanto en cuanto es el eje vertebrador de la experiencia cultural.

La creación que parte de la creación de otros, eso sería la labor curatorial. No es algo insólito, crear una obra de arte a partir de otras antecedentes es una práctica antigua y normalizada, aparte de una constante histórica. Así como pone de manifiesto Wilde, los grandes artistas "desde Homero y Esquilo a Shakespeare y Keats, no tomaron sus temas directamente de la vida, sino que los buscaron en la mitología, la leyenda y los antiguos cuentos" así el comisario "parte de materiales que otros han purificado, por decirlo así, para él, y que poseen ya además la forma imaginativa y el color" ${ }^{26}$. Hay mucha información al respecto. Los pintores en sus procesos de aprendizaje siempre han copiado a los grandes maestros de la antigüedad. En el caso literario, por ampliar el ejemplo de Wilde, Chaucer reprodujo en sus Cuentos de Canterbury la estructura del Decamerón de Bocaccio, es decir, un recopilatorio de micro-narraciones -unas originales y otras no- que puestas en boca de diferentes personajes están contenidas en una narrativa mayor. Mientras que el mismo Decamerón y Boccaccio es el espejo donde se van a mirar también la mayoría de los autores que hoy consideramos "clásicos", como el mismo Shakespeare o Cervantes, por ejemplo en sus Novelas Ejemplares.

En este sentido de reinterpretación, Wilde además sentencia:

21 TORRE AMERIGHI, Iván de la: "El proceso curatorial como obra de arte; el comisario como artista. Aproximaciones al debate y la crítica en torno a las debilidades, problemáticas y capacidad de transformación de la acción curatorial y el proyecto expositivo en la actualidad”'. En Revista Historia Autónoma, nº 4, 2014, págs. 166.

22 TORRE AMERIGHI, Iván de la: 2014, págs. 165-166.

${ }^{23}$ Esto podemos basarlo en una trasposición de lo expuesto por Wilde en su ensayo "El crítico como artista". WILDE, Oscar: 2000, pág. 33.

${ }^{24}$ WILDE, Oscar: 2000, pág. 18.

${ }^{25}$ SANTACANA MESTRE, Joan y HERNÁNDEZ CARDONA, Francesc Xavier: Museología crítica, Gijón, Trea, 2006, pág. 291.

${ }^{26}$ WILDE, Oscar: 2000, pág. 16. 
Cuando Rubinstein ejecuta la Sonata apassionata, de Beethoven, nos da no solamente a Beethoven, sino también a él mismo, así nos da a Beethoven de un modo completo, reinterpretado por una rica naturaleza artística, vivificado y espléndido, gracias a una nueva e intensa personalidad. Del mismo modo, cuando un gran actor representa obras de Shakespeare, pasamos por idéntica experiencia. Su individualidad se convierte en una parte esencial de la interpretación. ${ }^{27}$

La interpretación, la relectura del comisario, es un hecho propio de la contemporaneidad. En el siglo XVIII, en el momento mismo del surgimiento de la exposición pública se planteaba ésta como una enciclopedia artística. Con el paso del tiempo, la sustitución de esa función pedagógica de la exposición por otros medios más accesibles e instantáneos como los libros o, posteriormente, los medios digitales - preconizados como hemos señalado anteriormente, por Malraux-, ha liberado en cierto sentido al comisario de optar por una museología fija, clara y prefijada, en beneficio de formas de mostrar más frescas y exploradoras.

Estoy convencido: el estadio natural que ha de darse en esta evolución es la conversión de la exposición en una suerte de visita ante todo de carácter estético y experiencial. La conversión de lo que en principio eran actividades funcionales y prácticas en otras que no tienen ningún rendimiento productivo, es una característica propia sólo del ser humano y en ella se observa el grado de desarrollo al que ha llegado la sociedad en que se inserta. ¿Qué sino ocurrió con el arte mismo? Desde la llamada teoría de la "magia simpática" prehistórica, pasando por la exaltación del poder imperial, eclesiástico o de propaganda, hasta llegar al arte por el arte enunciado entre otros por Ad Reinhardt, los fines prácticos del arte han sido sustituidos en la actualidad por el mero goce estético de la pieza.

Análogamente a lo ocurrido con el arte como creación, la exposición del arte ha de liberarse de cualquier tipo de servidumbre, y emancipada, constituirse en obra de arte per se.

La exposición es un arte y el comisario, un artista

${ }^{27}$ WILDE, Oscar: 2000, pág. 22. 
Bibliografía

Ávila, A.: El arte y sus museos, Barcelona, Ediciones del Serbal, (2003).

Belda Navarro, C. y Marín Torres, $\mathrm{M}^{\mathrm{a}} \mathrm{T}$. (eds.): La museología y la Historia del Arte, Murcia, Servicio de publicaciones de la Universidad de Murcia, (2006).

Bernárdez Sanchís, C.: Joseph Beuys, Madrid, Nerea, (2003).

Bolaños, Ma . (ed.): La memoria del mundo. Cien años de museología 1900-2000, Gijón, Trea, (2002).

Groy, B.: "On the Curator-ship". En Art Power, Cambridge, MIT Press, (2008), pág. 43-51.

Borrego Pimentel,E. Mª: Cuestiones plotinianas, Granada, Biblioteca Teológica Granadina, (1994).

Checa Cremades, F.: Felipe II, Mecenas de las artes, Madrid, Nerea, (1992).

Debord, G.: La sociedad del espectáculo, Valencia, Pre-textos, (2010).

Didi-Huberman, G.: "La exposición como máquina de guerra: keywords". En Minerva. Revista del Círculo de Bellas Artes, no. 16, (2011), pp. 24-28.

Fernández López, O.: “Comisariado y exposiciones. Perspectivas historiográficas". En Exitbook: revista de libros de arte y cultura visual, $n^{\circ}$ 17, (2012), pp. 52-60.

Gau Pudelko, S.: El proceso de creación artística: diálogo con lo inefable, La Laguna Universidad de La Laguna, (2003).

Greenberg, R., Ferguson, B. W. y Nairne, S.: Thinking about exbibitions, Londres, Softcover, (1996).

Guasch, A.Ma.$:$ 2006. P. 114. La crítica dialogada: entrevistas sobre arte y pensamiento actual (2000-2006), Murcia, Cendeac, 2006.

Ledo, A.: "Aprender a comisariar. Cuestión y práctica". En Quintana, revista de estudios do Departamento de Historia da Arte, $n^{\circ} 11,2012$, pp. 329-333.

Molins De La Fuente, P.: "Las exposiciones temporales como campo de investigación en el museo de arte contemporáneo". En Arbor: Ciencia, pensamiento y cultura, N ${ }^{\circ} 717$, (2006), pp. 83-86.

Santacana Mestre, Joan y Hernández Cardona, Francesc Xavier: Museología crítica, Gijón, Trea, (2006).

Tejeda Martín, I.: El montaje expositivo como traducción. Fidelidades, traiciones y hallazgos en el arte contemporáneo desde los años 70, Madrid, Trama, 2006.

Torre Amerighi, I. De la : "El proceso curatorial como obra de arte; el comisario como artista. Aproximaciones al debate y la crítica en torno a las debilidades, problemáticas y capacidad de transformación de la acción curatorial y el proyecto expositivo en la actualidad”. En Revista Historia Autónoma, n. 4, (2014), pp. 157-172.

Ulrich Obrist, H.: Breve historia del comisariado, España, Exit, (2010).

Wilde, O.: El crítico como artista, Madrid, Espasa Calpe, (2000). 